\title{
Embryonic development in Arabidopsis thaliana: from the zygote division to the shoot meristem
}

\author{
Sonia Boscá, Steffen Knauer and Thomas Laux* \\ Faculty of Biology, BIOSS Centre for Biological Signalling Studies, University of Freiburg, Freiburg, Germany
}

Edited by:

Andreas P. M. Weber, University of

Duesseldorf, Germany

\section{Reviewed by:}

Dolf Weijers, Wageningen University,

Netherlands

Shinichiro Sawa, Kumamoto

University, Japan

*Correspondence:

Thomas Laux, Faculty of Biology,

BIOSS Centre for Biological Signalling

Studies, University of Freiburg,

Schaenzlestr. 1, 79104 Freiburg,

Germany.

e-mail: laux@biologie.uni-freiburg.de
Postembryonic organ formation of plants is fueled with cells from the stem cell niches in the shoot and root meristems. During the last two decades many players that regulate stem cell maintenance have been identified. With these factors in hand, the mechanisms establishing stem cell niches during embryo development can be addressed. Here we discuss current models of how the shoot meristem stem cell niche arises during Arabidopsis embryo pattern formation.

Keywords: stem cell niche, asymmetry, body plan, cell fate

\section{ORGANIZATION AND KEY FACTORS OF THE SHOOT MERISTEM}

In dicotyledonary angiosperms the shoot meristem is organized in three cell layers that contribute differentially to plant growth (Figure 1). The outermost L1 and the underlying L2 divide predominantly periclinally and give rise to the epidermis and subepidermal tissue. The $\mathrm{L} 3$ divides in all directions and gives rise to inner tissue. Clonal studies have determined that all postembryonically formed shoot cells ultimately are derived from about three stem cells in each layer (Stewart and Dermen, 1970). They are located in the outermost area of the central zone $(\mathrm{CZ})$ that is defined by a lower cell division rate, compared to the peripheral zone (PZ) where lateral organ anlagen are initiated, and the underlying rib zone (RZ) that forms the pith tissue (Lyndon, 1998).

The plant specific homeobox gene WUSCHEL (WUS) is expressed in the organizing center (OC), a small group of L3 cells (Figure 1). WUS is required to maintain the stem cells undifferentiated and for CLAVATA3 (CLV3) expression therein (Mayer et al., 1998; Schoof et al., 2000). CLV3 serves as a negative feedback signal that binds to several leucine-rich-repeat receptor-like kinases, including CLAVATA1 (CLV1; Fletcher et al., 1999; Rojo et al., 2002; Ogawa et al., 2008), to restrict the OC by downregulating WUS transcription (Lenhard and Laux, 2003). This negative feedback loop between OC and stem cells provides a conceptual framework for how stem cell number can be dynamically kept constant (Schoof et al., 2000).

The SHOOTMERISTEMLESS (STM) gene, similar to its maize ortholog KNOTTED1, is expressed throughout the meristem dome but is absent from incipient organ anlagen (Long et al., 1996). STM maintains meristem cell fate by directly promoting cytokinin synthesis and repressing accumulation of the cytokinin antagonist gibberellic acid (Hay et al., 2002; Jasinski et al., 2005; Yanai et al., 2005). In addition, STM prevents expression of ASYMMETRIC LEAVES1 (AS1), a repressor of the meristem genes
BP/KNAT1 and KNAT2. Opposite to the shoot meristem, leaf primordia are marked by the accumulation of auxin and gibberellins, and by the expression of $A S 1 / 2$, which together promote differentiation (Byrne et al., 2000, 2002; Hay et al., 2006).

\section{SETTING UP THE APICAL EMBRYO POLE}

Due to a largely invariant cell division pattern, the origin of the shoot meristem can be traced back to cellular decisions during Arabidopsis early embryogenesis (Figure 2). As in most plants investigated, the Arabidopsis zygote divides asymmetrically to give rise to two daughter cells of different developmental perspectives (Figures 2A,B). While the larger and highly vacuolated basal cell forms mainly the extra embryonic suspensor (the basal lineage), the small densely cytoplasmic apical cell gives rise to most of the embryo (the apical lineage). In the eight-cell embryo, the upper tier of four-cells are the founders of the shoot, including the shoot meristem, whereas the lower tier give rise to hypocotyl and embryonic root (Jürgens and Mayer, 1994). By a round of periclinal divisions, the eight-cell embryo separates the protoderm from inner cells. Subsequently, elongated cells in the lower half indicate the onset of vascular development. At the globular embryo stage, periclinal cell divisions at the two flanks result in an outgrowth of cotyledon primordia. Soon thereafter the three layered shoot meristem is visible between the growing cotyledons at the late heart stage.

Thus the shoot meristem originates through a series of formative cell divisions from the asymmetric division of the zygote onward. Mutant and gene expression studies have provided an entry point to analyze these early processes.

Important information for the asymmetric division of the zygote comes from the pollen which provides mRNA of the SHORT SUSPENSOR (SSP) gene (Bayer et al., 2009). SSP encodes an interleukin-1 receptor-associated kinase/Pelle-like kinase and genetically is upstream of YODA, a MAPKK kinase (Figure 2A). 


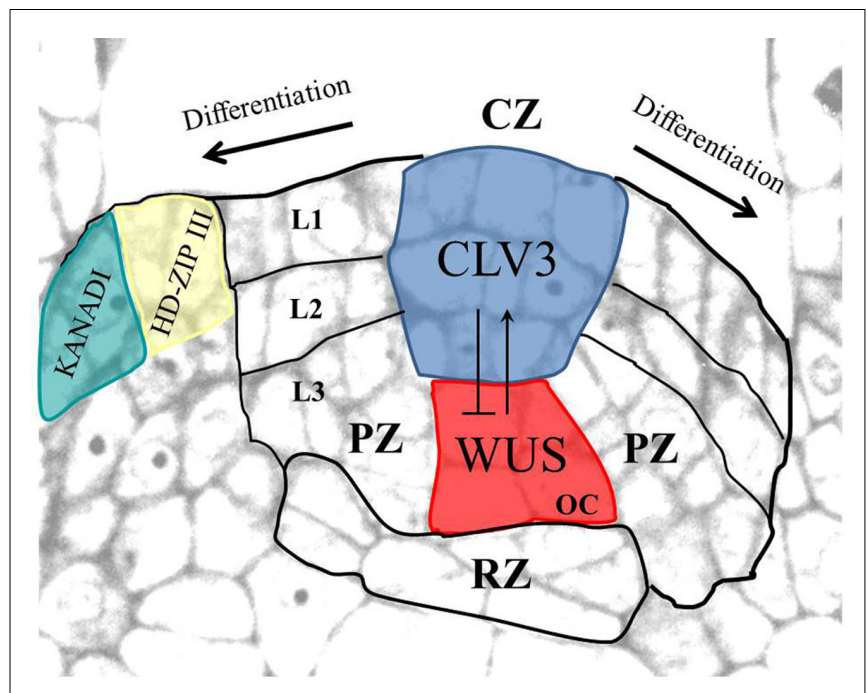

FIGURE 1 | Arabidopsis shoot apical meristem organization. The shoot meristem with the central zone (CZ), the peripheral zone (PZ), and the rib zone $(R Z)$ is shown. The three layers (L1-L3) are indicated. Stem cells (shown in blue, expressing CLV3) and the organizing center (OC; shown in red, expressing WUS) interact in a negative feedback loop. In the leaf primordium, adaxial and abaxial cell fates are marked by expression of HD-ZIP III and KANADI family genes, respectively. Modified from Gross-Hardt and Laux (2003).

The absence of SSP, YDA, or the downstream transcription factor GROUNDED (GRD) leads to failure of zygote elongation, a more symmetric division, and mis-specification of suspensor fate (Lukowitz et al., 2004; Bayer et al., 2009). Mutations in the WRKY2 gene also result in a more symmetric division of the zygote (Ueda et al., 2011). Here, it is the shift of the nucleus to the upper half of the zygote and the accumulation of vacuoles in the basal half that unlike wildtype do not take place in the wrky2 mutant, indicating a role for WRKY2 in establishing polar organization of the zygote. Subsequently, the two daughter cells in wrky 2 not only are of similar size but also both contain prominent vacuoles, in contrast to wildtype where prominent vacuoles are a hallmark of the basal daughter cell. Future work will reveal how YDA and WRKY2 pathways are interconnected in the zygote.

WRKY2 directly activates transcription of WOX 8 and presumably also of the redundant WOX9 gene in the zygote (Ueda et al., 2011). WOX8 expression is sufficient to rescue wrky2 polarity defects indicating that this interaction is relevant for zygote asymmetry. WOX8/9 are members of the intermediate clade of the WUSCHEL HOMEOBOX (WOX) gene family; and both genes are expressed in the zygote and in its basal derivatives (Figure 2B; Haecker et al., 2004). Together with WOX8/9 the zygote expresses WOX2, which is restricted to the apical cell after the zygotic division, and subsequently to the upper half of the dermatogen embryo (Haecker et al., 2004).

WOX8/9 act redundantly in the development of the suspensor, but also non-cell autonomously in the development of the apical derivatives of the zygote (Breuninger et al., 2008), where WOX8/9 are required for expression of WOX2. WOX2 in turn, together with WOX1, WOX3/PRS, and WOX5, redundantly functions in shoot

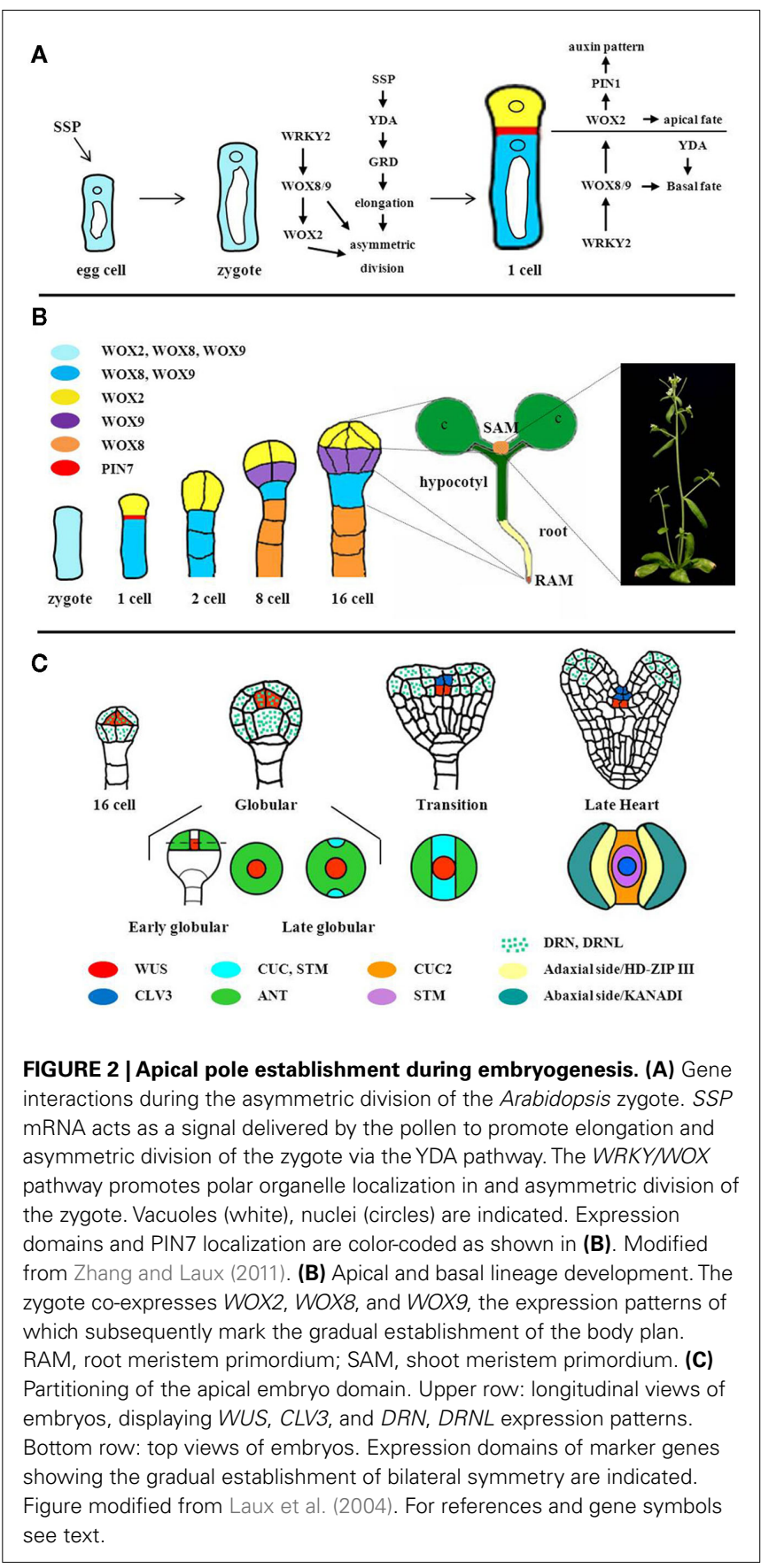

development, including expression of PIN-FORMED (PIN1), polar distribution of auxin, protoderm separation, and cotyledon spacing (Breuninger et al., 2008). Comparison of multiple mutant phenotypes indicates that WOX2 is the main regulator of embryonic shoot patterning, whereas WOX1,WOX3/PRS, and WOX5 only become relevant if WOX2 is mutant. Previous reports highlighted the importance of auxin accumulation in the embryo proper via PIN7-mediated transport as an important step for apical-basal axis formation and cotyledon spacing (Friml et al., 2003). One interesting question to be addressed in the future is whether WOX activity is also linked to PIN7 expression and 
auxin patterns from the one-cell embryo stage. In line with phenotypic differences between $y d a$ and wox8 wox9 mutants, triple mutant combinations indicate that both activities converge early in embryogenesis (Breuninger et al., 2008).

Together, these findings have suggested that the zygote expresses a mixture of basal and apical lineage regulators and that distortion of this balance affects the asymmetry of the zygotic division.

\section{INITIATION OF THE SHOOT MERISTEM STEM CELL NICHE}

Soon after apical and basal embryo lineages are established, shoot and root stem cell niches become apparent. Shoot and root fate involve complementary master regulators, HD-ZIPIII, and PLETHORA transcription factors, respectively. Ectopic expression of the HD-ZIPIII factor REVOLUTA ( $R E V$, see below) in the root pole is sufficient to convert the root into a second shoot structure by antagonizing PLETHORA (PLT) activity (Smith and Long, 2010). Vice versa, ectopic expression of PLT in the shoot pole of topless mutants causes a shoot to root transition.

In 16-cell wildtype embryos, WUS expression is initiated in the four inner cells of the apical embryo, which by a series of asymmetric divisions will give rise to the OC (Mayer et al., 1998; Figure 2C). Interestingly, however, the earliest defects observed in wus mutants are in heart stage embryos, when the cells and the structure of the shoot meristem primordium are abnormal. The role of WUS during the 16-cell to heart transition is yet unknown. Notably, WUS has been found to act also in female gametogenesis and male organ development (Deyhle et al., 2007; Lieber et al., 2011). In analogy, yet undiscovered functions of WUS unrelated to stem cell development cannot be excluded during early embryogenesis. Alternatively, it is possible that WUS solely acts to specify the precursor cells of the OC.

Which factors establish early WUS expression? Since WOX2 and WUS expression domains overlap at the 16-cell stage (Mayer et al., 1998; Haecker et al., 2004) and wox1,2,3,5 quadruple mutants are unable to form a shoot (Breuninger et al., 2008), WOX2 appears a plausible candidate that needs to be addressed. Several other mutants display an altered WUS expression pattern at later stages. For example, the DORNRÖSCHEN (DRN) gene is expressed from the one-cell embryo in the embryo proper and in drn dornröschen-like mutants, WUS expression is shifted laterally in the early globular embryo (Chandler et al., 2011), suggesting that $D R N / D R N L$ are required to position the OC.

Two factors, SPLAYED (SYD) and BARD1 (Kwon et al., 2005; Han et al., 2008) directly affect WUS expression. SYD, a SNF2class ATPase is required for efficient transcription of WUS, whereas $B A R D 1$, previously implicated in DNA repair, is required to repress WUS in the stem cells and confine its expression to the OC of seedling meristems. Both factors are expressed during early embryogenesis, raising the possibility that chromatin regulation is involved also in early stages of the WUS expression pattern.

CLV1 and CLV3 mRNA have been detected in the shoot meristem primordium as early as the heart embryo stage (Figure 2C; Long and Barton, 1998; Fletcher et al., 1999). clv1 and $c l v 3$ mutants display an increased expression domain of WUS from heart stage on, indicating the CLV signaling cascade is functional (Schoof et al., 2000). On the other hand, CLV3 expression is absent in mature wus embryos (Brand et al., 2002), showing that WUS is required for $C L V 3$ expression during embryogenesis. It will be of interest to determine the onset of CLV3 expression, the role of WUS therein, and the initiation of the WUS/CLV3 feedback regulation in the embryo.

\section{SETTING UP THE SHOOT MERISTEM PRIMORDIUM IN THE GLOBULAR EMBRYO}

The apical half of the globular embryo becomes partitioned into two lateral organ primordia and a central stripe that develops into the shoot meristem. Kaplan and Cooke (1997) propose that initiation of cotyledons is equivalent to initiation of leaves and thus that the apical domain of the embryo constitutes the first shoot meristem. However, with the discovery of stem cell regulators, the emerging picture is that many components of a self-maintaining meristem are still missing in the globular embryo. This suggests that cotyledon initiation, albeit morphologically similar to postembryonic leaf initiation, uses a different genetic repertoire than the postembryonic shoot meristem.

Establishing bilateral symmetry of the embryo and specification of the center as shoot meristem primordium involves an interplay of auxin, CUP-SHAPED COTYLEDON (CUC) genes, and the STM gene. At the globular embryo stage, CUPSHAPED COTYLEDON (CUC) genes CUC1 and CUC2 are expressed in a narrow stripe separating the presumptive cotyledonary primordia (Figure 2C; Aida et al., 1999; Takada et al., 2001). Detailed expression studies indicate that PIN1 and the auxin response factor MONOPTEROS are required to confine CUC1 expression to the central stripe and to enhance CUC2 expression therein (Aida et al., 2002), supporting an important role for auxin in the establishment of bilateral symmetry. CUC1 and CUC2 activities in turn are required to initiate STM expression and overexpression of CUC1 induces the formation of ectopic meristems, indicating CUCs as promoters of shoot meristem fate (Takada et al., 2001). During shoot meristem formation, STM appears to fulfill two functions: repression of cell division in the margins of the $\mathrm{CZ}$ to allow separation of cotyledons, and maintenance of shoot meristem cells in the center (Figure 2C; Long et al., 1996). Recent studies using postembryonic tissue revealed that STM can in turn promote expression of CUC1/2/3 genes (Spinelli et al., 2011). In addition, STM also represses CUC1/2 genes by indirectly activating MIR164a which targets CUC mRNA, suggesting the potential for positive and negative feedback loops between $S T M$ and CUC genes. It will be important to compare the precise spatio-temporal expression patterns and requirements for STM, $M I R 164 a$, and CUC genes during embryogenesis in order to evaluate the impact of these different interactions for shoot meristem initiation.

At the same time when the median stripe is specified, the peripheral regions initiate cotyledonary primordia. Expression of the AINTEGUMENTA (ANT) gene marks a peripheral ring of the globular embryo that overlaps with the central STM expression stripe; setting up two lateral regions that express $A N T$ but not $S T M$ and that will give rise to the cotyledons (Figure $2 \mathrm{C}$; Long and Barton, 1998). Afterward, ANT expression is confined to the cotyledons, together with AS1 that, in analogy to leaves, might downregulate the meristem genes KNAT1 and KNAT2 to allow differentiation (Byrne et al., 2000; Ori et al., 2000). 
At the transition stage, when cotyledonary primordia just became visible, auxin response maxima appear at the tips of the forming cotyledons due to polarized transport mediated by PIN1 (Benkova et al., 2003). This situation is somewhat reminiscent to the initiation of lateral organs in the postembryonic meristem (Braybrook and Kuhlemeier, 2010). However, whereas in the shoot meristem auxin response maxima predict the site of future organs, during embryogenesis, auxin accumulation is only observed after the cotyledons are established. Thus, auxin might function in cotyledon development at a later step than in the shoot meristem. Alternatively, low levels of auxin response that escaped the detection might determine the cotyledon positions.

\section{THE MERISTEM GOES TO WORK: ROLE OF ZWILLE EXPRESSION IN THE VASCULATURE}

Loss-of-function mutants of the ZWILLE gene (ZLL; also called PINHEAD and AGO10) lack a shoot meristem at the seedling stage and instead display an empty apex, indistinguishable from wus seedlings, or a differentiated leaf structure (Mcconnell and Barton, 1995; Moussian et al., 1998). In contrast to wus mutants, however, zll seedlings can form indeterminate shoot meristems after germination, indicating an essential role during embryonic shoot meristem development (Endrizzi et al., 1996; Moussian et al., 1998). zll embryos express WUS, and also initiate CLV3 expression, but subsequently $C L V 3$ expression is not maintained despite the presence of WUS (Tucker et al., 2008). Furthermore, overexpression of WUS is ineffective in a zll mutant. This indicates that ZLL is required to potentiate WUS dependent signaling from the OC to maintain stem cell identity and $C L V 3$ expression.

$Z L L$ encodes a member of the ARGONAUTE proteins that are central components in RNA interference (Moussian et al., 1998; Hutvagner and Simard, 2008). Interestingly, ZLL expression in the vascular primordium is sufficient to rescue stem cell maintenance, indicating a non-cell autonomous mechanism by which the vasculature sustains the overlying shoot meristem (Tucker et al., 2008). Since ZLL protein itself does not seem to move (Moussian et al., 2003), what might be a signal emanating from vascular cells? Liu et al. (2009) discovered that in zll mutants, miR165/166 accumulates in the shoot meristem primordium and in turn their targets, class III HD-ZIP mRNAs REVOLUTA (REV), PHABULOSA (PHB), and AtHB15 are reduced. HD-ZIPIII genes encode homeodomain transcription factors and have overlapping and antagonistic roles in shoot meristem maintenance, adaxialabaxial polarity, and vascular development (Prigge et al., 2005; Byrne, 2006). miR165/6 expression overlaps with transcripts of the HD-ZIP III mRNAs during cotyledon development and in the shoot meristem of mature embryos, suggesting that miR165/6 tunes the steady state levels of its targets mRNAs (Williams et al., 2005).

Since shoot meristem development was restored in zll mutants by miRNA resistant versions of $R E V$ or $P H B$ and by reduction of miRNA165/166 levels via mimicry RNAs (Liu et al., 2009), the accumulation of miR165/166 appears to be the cause of shoot meristem loss in the zll mutant. AGO proteins normally bind miRNAs to either degrade or translationally inhibit their target mRNAs, and therefore, the increase of HD-ZIPIII RNAi in the absence of ZLL is somewhat paradoxical. It was noted before, however, that ZLL not only can act in RNAi (Brodersen et al., 2008), but also can antagonize gene silencing and developmental functions of AGO1, a major AGO protein in mRNA degradation (Mallory et al., 2009). One interesting model proposed therefore is that ZLL might bind in the vasculature to miR165/166 and thus block its accumulation in the shoot meristem primordium (Braybrook and Kuhlemeier, 2010; Chitwood and Timmermans, 2010). In line with this model, the ability of miR165/6 to move between cells has been reported (Carlsbecker et al., 2010). Furthermore, biochemical evidence shows that ZLL specifically binds to the duplex of miR166/166* with a higher affinity than AGO1. Importantly, in vitro RNAi experiments indicate that ZLL appears to be less efficient than AGO1 in degrading HD-ZIPIII mRNA. Therefore, ZLL might function by sequestering miR165/166 away from the catalytically more active AGO1, resulting in higher HD-ZIPIII mRNA levels (Figure 3; Zhu et al., 2011).

\section{INTERPLAY OF LEAF PATTERNING AND SHOOT MERISTEM MAINTENANCE}

Analysis of the phantastica (phan) mutant in Antirrhinum by Waites et al. (1998) showed that shoot meristem maintenance requires signals from its descendants, the leaves. In addition to defects in adaxial-abaxial leaf polarity, phan mutants grown at low temperatures fail to maintain the shoot meristem. Notably, PHAN mRNA was exclusively detected in lateral organ initials, implying signaling from leaf primordia back to the shoot meristem.

Mutants of adaxial-abaxial leaf polarity genes in Arabidopsis corroborate this notion. The miRNA resistant mutant phb1-d gives rise to adaxialized leaves, bearing ectopic shoot meristems on the lower side (Mcconnell and Barton, 1998). Vice versa, multiple HD-ZIPIII mutant seedlings variably display abaxialized cotyledons and shoot meristem termination (Emery et al., 2003; Prigge et al., 2005). Thus, in addition to HD-ZIPIII gene expression in

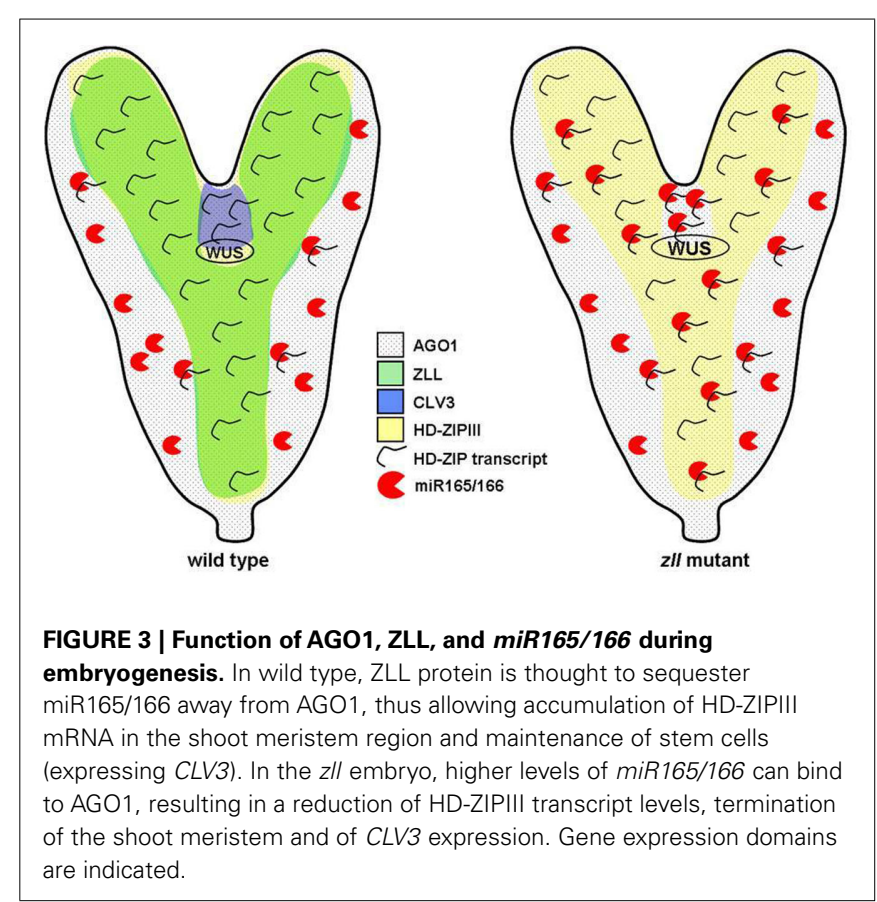


the meristem primordium, their role in leaf primordia patterning might also be required for shoot meristem formation, but distinguishing these two functions still needs to be addressed. Opposite to HD-ZIPIII genes, overexpression of KANADI (KAN) genes, which antagonize HD-ZIPIII functions in leaf development and promote abaxial development, result in termination of the shoot meristem (Kerstetter et al., 2001; Izhaki and Bowman, 2007). These data together indicate that an adaxial environment promotes shoot meristem formation, whereas abaxial features antagonize it. The nature of the underlying hypothetical leaf borne signal(s) is yet to be determined.

\section{PERSPECTIVES}

During the past decade important players that are involved in building the Arabidopsis embryo have been identified. Many of those were found based on postembryonic mutant phenotypes; it is thus not surprising that currently our knowledge of embryo patterning is biased toward the initiation of postembryonic networks.

\section{REFERENCES}

Aida, M., Ishida, T., and Tasaka, M. (1999). Shoot apical meristem and cotyledon formation during Arabidopsis embryogenesis: interaction among the cup-shaped cotyledon and shoot meristemless genes. Development 126, 1563-1570.

Aida, M., Vernoux, T., Furutani, M., Traas, J., and Tasaka, M. (2002). Roles of pin-formed 1 and monopteros in pattern formation of the apical region of the Arabidopsis embryo. Development 129 , 3965-3974.

Bayer, M., Nawy, T., Giglione, C., Galli, M., Meinnel, T., and Lukowitz, W. (2009). Paternal control of embryonic patterning in Arabidopsis thaliana. Science 323, 1485-1488.

Benkova, E., Michniewicz, M., Sauer, M., Teichmann, T., Seifertova, D., Jürgens, G., and Friml, J. (2003). Local, efflux-dependent auxin gradients as a common module for plant organ formation. Cell 115, 591-602.

Brand, U., Grunewald, M., Hobe, M., and Simon, R. (2002). Regulation of CLV3 expression by two homeobox genes in Arabidopsis. Plant Physiol. 129, 565-575.

Braybrook, S. A., and Kuhlemeier, C. (2010). How a plant builds leaves. Plant Cell 22, 1006-1018.

Breuninger, H., Rikirsch, E., Hermann, M., Ueda, M., and Laux, T. (2008). Differential expression of WOX genes mediates apical-basal axis formation in the Arabidopsis embryo. Dev. Cell 14, 867-876.

Brodersen, P., Sakvarelidze-Achard, L., Bruun-Rasmussen, M., Dunoyer, P., Yamamoto, Y. Y., Sieburth, L., and Voinnet, O. (2008). Widespread translational inhibition by plant miRNAs and siRNAs. Science 320 , 1185-1190.

Byrne, M. E. (2006). Shoot meristem function and leaf polarity: the role of class III HD-ZIP genes. PLoS Genet. 2, e89. doi:10.1371/journal.pgen.0020089

Byrne, M. E., Barley, R., Curtis, M., Arroyo, J. M., Dunham, M., Hudson, A., and Martienssen, R. A. (2000). Asymmetric leaves 1 mediates leaf patterning and stem cell function in Arabidopsis. Nature 408, 967-971.

Byrne, M. E., Simorowski, J., and Martienssen, R. A. (2002). Asymmetric leaves1 reveals knox gene redundancy in Arabidopsis. Development 129, 1957-1965.

Carlsbecker, A., Lee, J. Y., Roberts, C. J., Dettmer, J., Lehesranta, S., Zhou, J., Lindgren, O., Moreno-Risueno, M. A., Vaten, A., Thitamadee, S., Campilho, A., Sebastian, J., Bowman, J. L., Helariutta, Y., and Benfey, P. N. (2010). Cell signalling by microRNA165/6 directs gene dosedependent root cell fate. Nature 465, 316-321.

Chandler, J. W., Cole, M., Jacobs, B., Comelli, P., and Werr, W. (2011). Genetic integration of dornroschen and dornroschen-like reveals hierarchical interactions in auxin signalling and patterning of the Arabidopsis apical embryo. Plant Mol. Biol. 75, 223-236.

Chitwood, D. H., and Timmermans, M. C. (2010). Small RNAs are on the move. Nature 467, 415-419.

Deyhle, F., Sarkar, A. K., Tucker, E. J., and Laux, T. (2007). WUSCHEL regulates cell differentiation during anther development. Dev. Biol. 302, 154-159.

Whether there is also an underlying set of embryo specific regulators not detected in conventional mutant screens remains to be determined. Genetic screens in sensitized backgrounds, searches for abnormal expression patterns, or reverse genetics starting from embryo cell specific expression profiles promise to provide insight. With the players known, high resolution of their spatio-temporal patterns of expression and function becomes a pressing issue. Live imaging in embryos will be thus a challenge for the coming years that holds the promise to allow insight into the regulatory logic that builds the body plan, as much as it has aided to decipher complex networks in postembryonic development.

\section{ACKNOWLEDGMENTS}

We thank Leron Katsir for critical comments on the manuscript. We apologize to colleagues whose work could not be included due to space constraints. We gratefully acknowledge support by the DFG grant La606/12 within the framework of the Arabidopsis Functional Genomics Network (AFGN).

Emery, J. F., Floyd, S. K., Alvarez, J., Eshed, Y., Hawker, N. P., Izhaki, A., Baum, S. F., and Bowman, J. L. (2003). Radial patterning of Arabidopsis shoots by class III HD-ZIP and KANADI genes. Curr. Biol. 13, 1768-1774.

Endrizzi, K., Moussian, B., Haecker, A. Levin, J., and Laux, T. (1996). The shoot meristemless gene is required for maintenance of undifferentiated cells in Arabidopsis shoot and floral meristems and acts at a different regulatory level than the meristem genes WUSCHEL and ZWILLE. Plant J. 10, 967-979.

Fletcher, J. C., Brand, U., Running, M. P., Simon, R., and Meyerowitz, E. M. (1999). Signaling of cell fate decisions by CLAVATA3 in Arabidopsis shoot meristems. Science 283, 1911-1914.

Friml, J., Vieten, A., Sauer, M., Weijers, D., Schwarz, H., Hamann, T., Offringa, R., and Jürgens, G. (2003). Efflux-dependent auxin gradients establish the apical-basal axis of Arabidopsis. Nature 426, 147-153.

Gross-Hardt, R., and Laux, T. (2003). Stem cell regulation in the shoot meristem. J. Cell Sci. 116, 1659-1666.

Haecker, A., Gross-Hardt, R., Geiges, B., Sarkar, A., Breuninger, H., Herrmann, M., and Laux, T. (2004). Expression dynamics of WOX genes mark cell fate decisions during early embryonic patterning in Arabidopsis thaliana. Development 131 , 657-668.

Han, P., Li, Q., and Zhu, Y. X. (2008). Mutation of Arabidopsis BARD1 causes meristem defects by failing to confine WUSCHEL expression to the organizing center. Plant Cell 20, 1482-1493.
Hay, A., Barkoulas, M., and Tsiantis, M. (2006). Asymmetric leaves1 and auxin activities converge to repress brevipedicellus expression and promote leaf development in Arabidop sis. Development 133, 3955-3961.

Hay, A., Kaur, H., Phillips, A., Hedden, P., Hake, S., and Tsiantis, M. (2002). The gibberellin pathway mediates knotted1-type homeobox function in plants with different body plans. Curr. Biol. 12, 1557-1565.

Hutvagner, G., and Simard, M. J. (2008). Argonaute proteins: key players in RNA silencing. Nat. Rev. Mol. Cell Biol. 9, 22-32.

Izhaki, A., and Bowman, J. L. (2007). KANADI and class III HD-Zip gene families regulate embryo patterning and modulate auxin flow during embryogenesis in Arabidopsis. Plant Cell 19, 495-508.

Jasinski, S., Piazza, P., Craft, J., Hay, A., Woolley, L., Rieu, I., Phillips, A., Hedden, P., and Tsiantis, M. (2005). KNOX action in Arabidopsis is mediated by coordinate regulation of cytokinin and gibberellin activities. Curr. Biol. 15, 1560-1565.

Jürgens, G., and Mayer, U. (1994). “Arabidopsis," in A Colour Atlas of Developing Embryos, ed. J. Bard (London: Wolfe Publishing), 7-21.

Kaplan, D. R., and Cooke, T. J. (1997). Fundamental concepts in the embryogenesis of dicotyledons: a morphological interpretation of embryo mutants. Plant Cell 9, 1903-1919.

Kerstetter, R. A., Bollman, K., Taylor, R. A., Bomblies, K., and Poethig, R. S. (2001). KANADI regulates organ polarity in Arabidopsis. Nature 411, 706-709. 
Kwon, C. S., Chen, C., and Wagner, D. (2005). WUSCHEL is a primary target for transcriptional regulation by splayed in dynamic control of stem cell fate in Arabidopsis. Genes Dev. 19, 992-1003.

Laux, T., Wurschum, T., and Breuninger, H. (2004). Genetic regulation of embryonic pattern formation. Plant Cell 16(Suppl.), S190-S202.

Lenhard, M., and Laux, T. (2003). Stem cell homeostasis in the Arabidopsis shoot meristem is regulated by intercellular movement of CLAVATA3 and its sequestration by CLAVATA1. Development 130, 3163-3173.

Lieber, D., Lora, J., Schrempp, S., Lenhard, M., and Laux, T. (2011). Arabidopsis WIH1 and WIH2 genes act in the transition from somatic to reproductive cell fate. Curr. Biol. 21, 1009-1017.

Liu, Q., Yao, X., Pi, L., Wang, H., Cui, X., and Huang, H. (2009). The ARGONAUTE10 gene modulates shoot apical meristem maintenance and leaf polarity establishment by repressing miR165/166 in Arabidopsis. Plant J. 58, 27-40.

Long, J. A., and Barton, M. K. (1998). The development of apical embryonic pattern in Arabidopsis. Development 125, 3027-3035.

Long, J. A., Moan, E. I., Medford, J. I., and Barton, M. K. (1996). A member of the knotted class of homeodomain proteins encoded by the STM gene of Arabidopsis. Nature 379, 66-69.

Lukowitz, W., Roeder, A., Parmenter, D., and Somerville, C. (2004). A MAPKK kinase gene regulates extraembryonic cell fate in Arabidopsis. Cell 116, 109-119.

Lyndon, R. F. (1998). The Shoot Apical Meristem: Its Growth and Development. Cambridge: Cambridge University Press.

Mallory, A. C., Hinze, A., Tucker, M. R., Bouche, N., Gasciolli, V., Elmayan, T., Lauressergues, D., Jauvion, V., Vaucheret, H., and Laux,
T. (2009). Redundant and specific roles of the argonaute proteins AGO1 and ZLL in development and small RNA-directed gene silencing. PLoS Genet. 5, e1000646. doi:10.1371/journal.pgen.1000646

Mayer, K. F., Schoof, H., Haecker, A., Lenhard, M., Jürgens, G., and Laux, T. (1998). Role of WUSCHEL in regulating stem cell fate in the Arabidopsis shoot meristem. Cell 95, 805-815.

Mcconnell, J. R., and Barton, M. K. (1995). Effects of mutations in the PINHEAD gene of Arabidopsis on the formation of shoot apical meristems. Dev. Genet. 16, 358-366.

Mcconnell, J. R., and Barton, M. K. (1998). Leaf polarity and meristem formation in Arabidopsis. Development 125, 2935-2942.

Moussian, B., Haecker, A., and Laux, T. (2003). ZWILLE buffers meristem stability in Arabidopsis thaliana. Dev. Genes Evol. 213, 534-540.

Moussian, B., Schoof, H., Haecker, A., Jürgens, G., and Laux, T. (1998). Role of the ZWILLE gene in the regulation of central shoot meristem cell fate during Arabidopsis embryogenesis. EMBO J. 17, 1799-1809.

Ogawa, M., Shinohara, H., Sakagami, Y., and Matsubayashi, Y. (2008). Arabidopsis CLV3 peptide directly binds CLV1 ectodomain. Science 319, 294.

Ori, N., Eshed, Y., Chuck, G., Bowman, J. L., and Hake, S. (2000). Mechanisms that control knox gene expression in the Arabidopsis shoot. Development 127, 5523-5532.

Prigge, M. J., Otsuga, D., Alonso, J. M., Ecker, J. R., Drews, G. N., and Clark, S. E. (2005). Class III homeodomain-leucine zipper gene family members have overlapping, antagonistic, and distinct roles in Arabidopsis development. Plant Cell 17, 61-76.

Rojo, E., Sharma, V. K., Kovaleva, V., Raikhel, N. V., and Fletcher, J. C. (2002). CLV3 is localized to the extracellular space, where it activates the Arabidopsis CLAVATA stem cell signaling pathway. Plant Cell 14 969-977.

Schoof, H., Lenhard, M., Haecker, A. Mayer, K. F., Jürgens, G., and Laux, T. (2000). The stem cell population of Arabidopsis shoot meristems in maintained by a regulatory loop between the CLAVATA and WUSCHEL genes. Cell 100 635-644.

Smith, Z. R., and Long, J. A. (2010). Control of Arabidopsis apical-basal embryo polarity by antagonistic transcription factors. Nature 464, 423-426.

Spinelli, S. V., Martin, A. P., Viola, I. L., Gonzalez, D. H., and Palatnik, J. F. (2011). A mechanistic link between STM and CUC1 during Arabidopsis development. Plant Physiol. 156, 1894-1904.

Stewart, R. N., and Dermen, H. (1970). Determination of number and mitotic activity of shoot apical initial cells by analysis of mericlinal chimeras. Am. J. Bot. 57, 816-826.

Takada, S., Hibara, K., Ishida, T., and Tasaka, M. (2001). The cup-shaped COTYLEDON1 gene of Arabidopsis regulates shoot apical meristem formation. Development 128, 1127-1135.

Tucker, M. R., Hinze, A., Tucker, E. J., Takada, S., Jurgens, G., and Laux, T. (2008). Vascular signalling mediated by ZWILLE potentiates WUSCHEL function during shoot meristem stem cell development in the Arabidopsis embryo. Development 135, 2839-2843.

Ueda, M., Zhang, Z., and Laux, T. (2011). Transcriptional activation of Arabidopsis axis patterning genes WOX8/9 links zygote polarity to embryo development. Dev. Cell 20, 264-270.

Waites, R., Selvadurai, H. R., Oliver, I. R., and Hudson, A. (1998). The phantastica gene encodes a MYB transcription factor involved in growth and dorsoventrality of lateral organs in Antirrhinum. Cell 93, 779-789.
Williams, L., Grigg, S. P., Xie, M., Christensen, S., and Fletcher, J. C. (2005). Regulation of Arabidopsis shoot apical meristem and lateral organ formation by microRNA miR166g and its AtHD-ZIP target genes. Development 132, 3657-3668.

Yanai, O., Shani, E., Dolezal, K., Tarkowski, P., Sablowski, R., Sandberg, G., Samach, A., and Ori, N. (2005). Arabidopsis KNOXI proteins activate cytokinin biosynthesis. Curr. Biol. 15, 1566-1571.

Zhang, Z., and Laux, T. (2011). The asymmetric division of the Arabidopsis zygote: from cell polarity to an embryo axis. Sex. Plant Reprod. 24, 161-169.

Zhu, H., Hu, F., Wang, R., Zhou, X., Sze, S. H., Liou, L. W., Barefoot, A. Dickman, M., and Zhang, X. (2011). Arabidopsis argonaute10 specifically sequesters miR166/165 to regulate shoot apical meristem development. Cell 145, 242-256.

Conflict of Interest Statement: The authors declare that the research was conducted in the absence of any commercial or financial relationships that could be construed as a potential conflict of interest.

Received: 16 September 2011; paper pending published: 01 October 2011; accepted: 20 November 2011; published online: 07 December 2011.

Citation: Boscá S, Knauer S and Laux T (2011) Embryonic development in Arabidopsis thaliana: from the zygote division to the shoot meristem. Front. Plant Sci. 2:93. doi: 10.3389/fpls.2011.00093

This article was submitted to Frontiers in Plant Physiology, a specialty of Frontiers in Plant Science.

Copyright () 2011 Boscá, Knauer and Laux. This is an open-access article distributed under the terms of the Creative Commons Attribution Non Commercial License, which permits non-commercial use, distribution, and reproduction in other forums, provided the original authors and source are credited. 